\section{Relationship between Parental Blossom Season and Speed of Seed Germination in Peach}

\author{
S. Pérez-González \\ INIFAP-Guanajuato/CENGUA, A.P. 112, Celaya, Gto., 3800 México \\ Additional index words. Prunus persica, spring frosts, chilling requirement
}

\begin{abstract}
A highly significant correlation was observed between time of bloom of individual peach trees [Prunus persica (L.) Batsch.] and number of days required for resulting selfed seed to reach $80 \%$ germination on both local $(r=0.71)$ and introduced $(r=0.87)$ genotypes that exhibited a wide range in time of blossom. When genotypes with low chilling requirement (LCR) were pollinated with high chilling requirement (HCR) pollen sources, germination was delayed up to 16 days with respect to seeds that originated from selfing, while LCR pollen sources on late-blossoming genotypes accelerated germination 20 to 24 days.
\end{abstract}

Peach is the main temperate fruit crop in central and southern Mexico, but annual production is strongly limited by freezing temperatures during bloom (Pérez, 1988). Attempts to avoid the problem have included: 1) orchard heating and overhead sprinkler irrigation (both increase production costs and lower the competitive capacity of the growers at the market), and 2) selection for late-blooming genotypes: Such selection has been localized and has not led to the developement of new cultivars that could escape late frosts.

Among wild species of plants, there is a close association between geographic origin and climatic-edaphic requirements for development as a result of long-term adaptation (Grant, 1981; Solbrig, 1980; Stebbins, 1950). Even though cultivated species have been removed from their original environments, they tend to maintain a certain "genetic integrity" by the association of gene complexes or linkage groups (Futuyma and Slatkin, 1983; Solbrig, 1980). Such associations have been important in characterizing some temperate fruit species, such as Pyrus (Westwood and Bjornstad, 1968) and Malus (Pasternak and Powell, 1980), where a close relationship was found between the place of origin and the chilling requirement of buds and seeds.

In some species of Prunus, such as almond (Kester, 1969; Kester et al., 1977) and peach (Chang and Werner, 1984; Díaz and Martin, 1972; Guerriero and Scalabrelli, 1985), a correlation exists between parental blooming season and chilling requirement of the seed. However, Rodríguez and Sherman (1985) were not able to separate the influence of pollen donors differing in chilling requirement on the speed of seed germination of various peach families that required between 100 anid 500 chill units.

Received for publication 18 Aug. 1989. The cost of publishing this paper was defrayed in part by the payment of page charges. Under postal regulations, this paper therefore must be hereby marked advertisement solely to indicate this fact.
The main objectives of this work were to test: 1) any positive correlation between time of blossom and chilling requirements of several feral peach populations in Mexico and of a group of introduced cultivars differing in time of blossom, and 2) the effect of pollen from genotypes with varying chilling requirement on the speed (number of days to reach $80 \%$ germination) and rate of seed germination (number of days elapsed between the first and last seeds to germinate) of some feral Mexican peaches. Such correlative response would allow the formation of seed families with respect to chilling requirement and blooming season for further testing of the possibility of escaping frost damage at various latitudes and altitudes.

Peach seedlings used for this study were transplanted in 1985-86 to a semi-arid region under irrigation with 400 to 600 chilling units and late winter-early spring frosts (northern Guanajuato in central Mexico). Seedlings were first grouped according to blossoming season, from extremely early to very late. In 1988-89, individual trees were covered with a fine plastic net during bloom to prevent outcrossing; then selfed seeds were collected.

The data were obtained from: 1) selfed introduced cultivars and selections from the United States, Italy, Spain, and Brazil; 2) selfed feral peach selections originally collected from the main peach growing regions in central Mexico between 1800- and 2500$\mathrm{m}$ altitude; and 3) feral Mexican peach selections showing early (II2-7), medium (CII32 ), and late blooming (14-22) that were pollinated with low (III-5D, Italia-1, 'FlordaGrande', and IV9-33) or high chilling requirement pollen sources ('FlavorCrest' and 'Elegant Lady').

At harvest, 70 to 160 seeds were collected from every self- or cross-pollinated combination. The pits were cracked and the seeds were surface sterilized with $3 \%$ sodium hypochlorite, rinsed twice in distilled water, and stratified at $5 \mathrm{C}$ on humid paper towels inside transparent plastic bags. Four to 10 replications of 16 seeds each were used for each progeny after 3 weeks in stratification. The bags were observed twice per week; germinated seeds were recorded and transplanted until all viable ones had germinated. Data were expressed as number of days required to reach $80 \%$ germination (germination speed), and Duncan's multiple range test was used to determine differences among means. Data were analyzed for correlations between parental blossom dates (days after 'Okinawa' first began to blossom) and number of days in stratification required to reach $80 \%$ germination.

Selfed genotypes. There was a significant correlation ( $r=0.71$ for local seedlings; $r$ $=0.87$ for introduced genotypes) between parental blossom dates and the number of days required for resulting selfed seed to reach $80 \%$ germination, confirming previous work with peach (Chang and Werner, 1984) and other species (Kester, 1969; Kester et al. 1977; Pasternak and Powell, 1980). Very low chilling genotypes that originated at low elevations in the tropics and subtropics, such as 'Okinawa' from the South Pacific, 'FlordaGrande', and N2-10 (a seedling selected from a locally grown Florida nectarine), all showing extremely early blooming under local conditions (mid-December), reached $80 \%$ germination in $\approx 50$ days or less. Most feral Mexican peach genotypes selected at higher elevations in the subtropics germinated within a range of 53 to 65 days under stratification. However, their blossom season still coincided with late winter-early spring frosts (one crop is lost every 4 to 7 years). All genotypes germinating within the 65- to 80-day stratification range, either local (14-22, 18-16, and IV18-9) or introduced (populations originating from 'Calanda'), belonged to late-blossoming genotypes with very high chances of escaping late frosts.

Introduced materials consisted of two welldifferentiated groups with respect to blooming season. One, which includes the highest proportion of genotypes studied, shows very early blooming and rapid germination, while the other group exhibits very late blossoming and requires more than 80 days under stratification to reach maximum germination (Fig. 1).

Previous work has emphasized the number of days required to reach $80 \%$ germination as the main factor related to chilling requirement. However, the germination range might explain some other sources of variation. For example, most feral Mexican seedlings show concentrated germination ranges and are known to produce highly uniform seedling populations with respect to blossom and growth habit (Pérez, 1989). However, most introduced cultivars exhibit very wide germination ranges, suggesting a hybrid origin between parents differing in chilling requirement. This can be clearly seen in the cross 'Emperor' $x$ 'Tetela Evergreen', where the parents differed in chilling requirement. This also happens with 'Italia-1' (ISF73110828), the only early blossoming seedling selected out of a segregating population introduced from Italy (Instituto Sperimentale per la Frutticoltura), the remainder producing few 


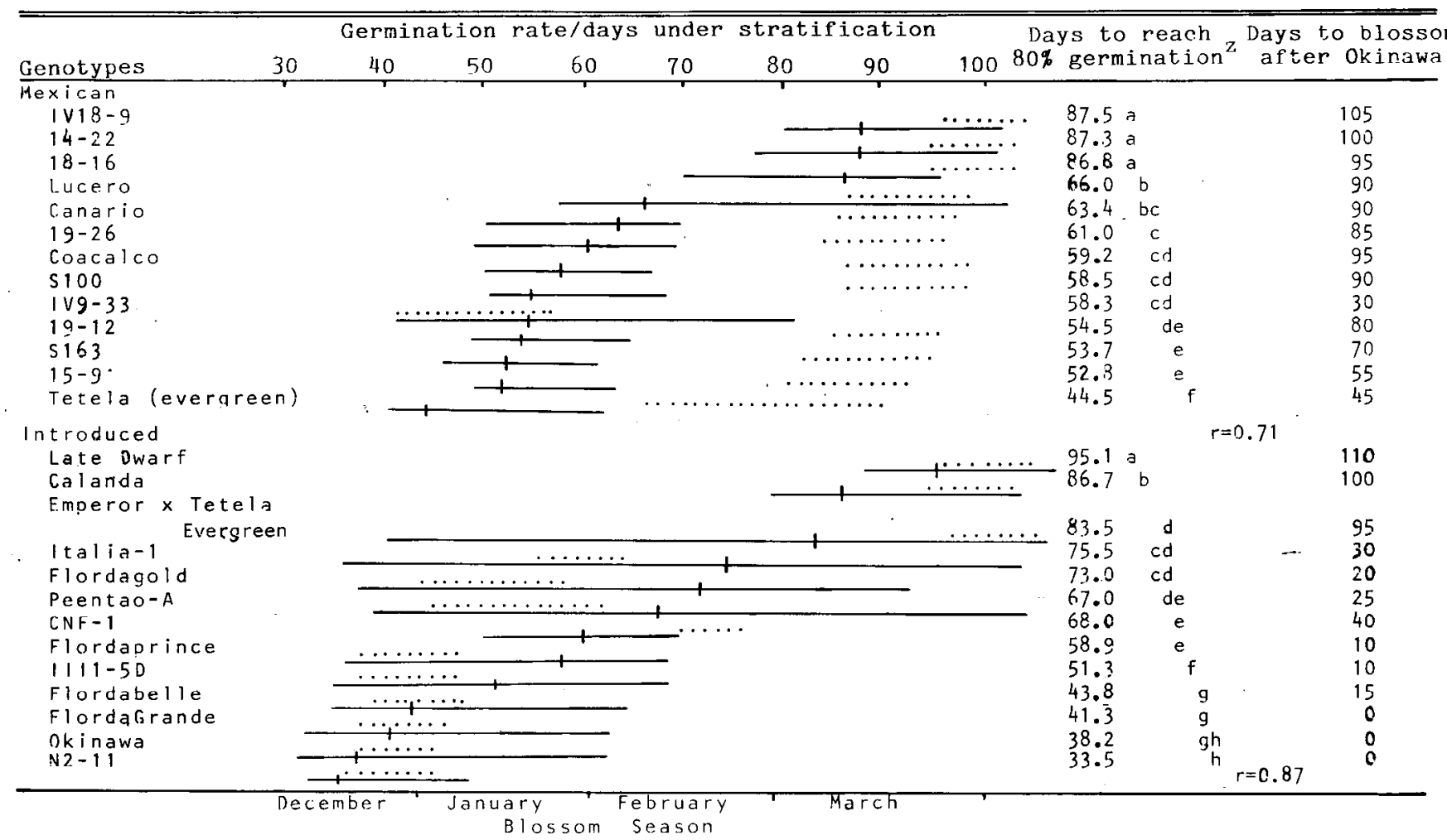

Fig. 1. Distribution and rate of seed germination during stratification at $5 \mathrm{C}$ of Mexican and introduced peach genotypes in relation to time of blossoming in northern Guanajuato, Mexico.

${ }^{2}$ Mean separation by Duncan's multiple range test $(P=0.05) \ldots=$ Season of blossom of parent tree; when $90 \%$ germination was achieved.

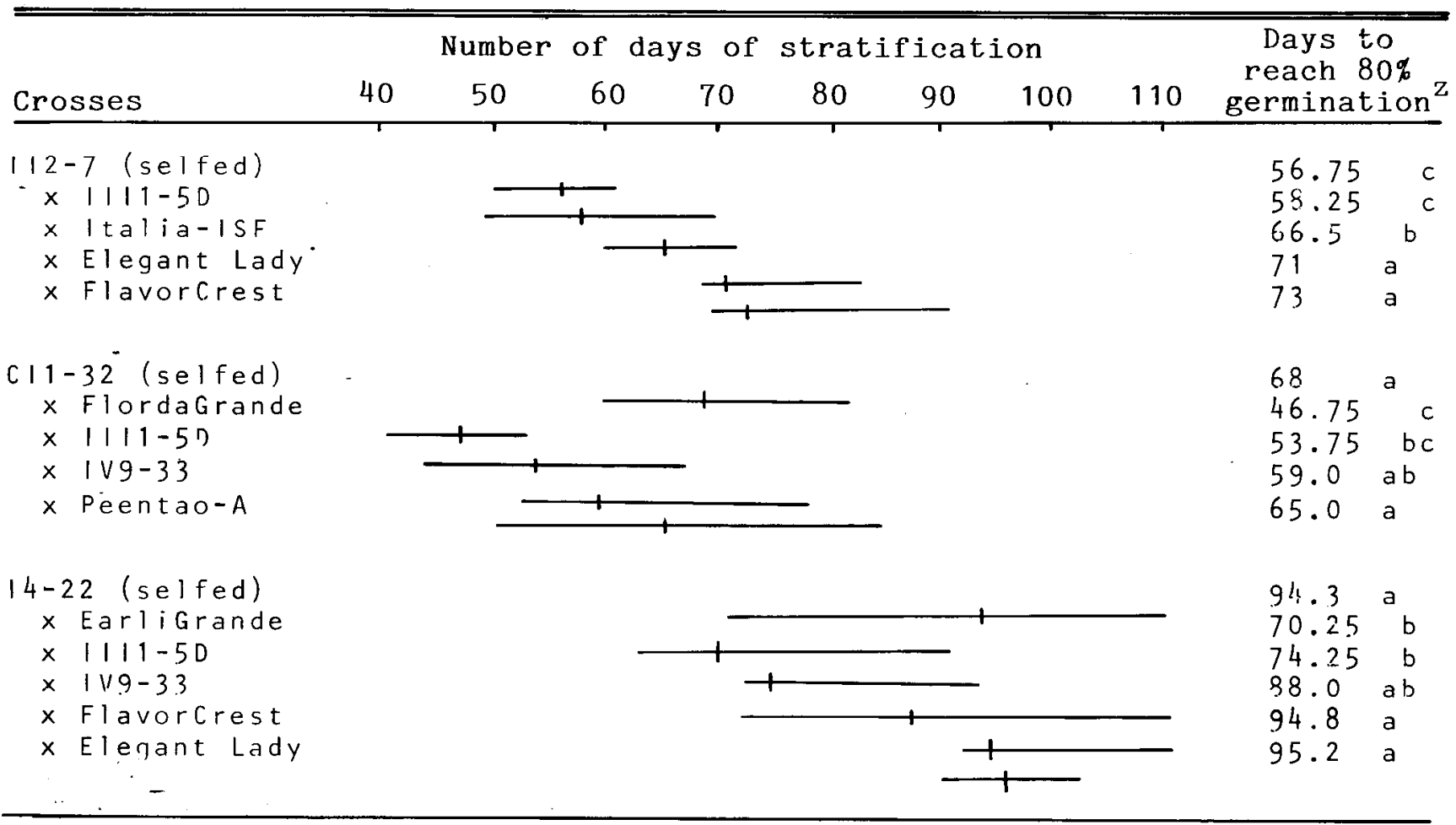

Fig. 2. Influence of pollen source on distribution over time and on rate of seed germination.

${ }^{2}$ Mean separation by Duncan's multiple range test $(P=0.05)$. Number of days to reach $80 \%$ germination.

blossoms due to inadequate chilling in $\mathrm{Gu}$ anajuato. However, they both reflect their genetic origin and show a high proportion of late-germinating seeds that represents a good source of variation in the search for lateblossoming genotypes (Fig. 1). Another difference between local seedlings and introduced cultivars is that the blossom seasons are skewed towards the late side of the germination curves for the feral Mexican genotypes vs. the early. side on almost all introduced cultivars. Theoretically, if we 
consider chilling requirement as the only factor involved in seed germination and blossoming season, local genotypes should either blossom earlier or their seeds should germinate later. This "discrepancy" might be the result of adaptation to a subtropical environment at high elevations. Here, days are, warm and nights cool during the winter, and those trees and seeds might also have a high heat requirement for blooming or germination. This subject demands further study.

Influence of pollen source on seed germination. The distribution and rate of seed germination were determined by the genetic origin of the parents involved in a given cross (Fig. 2). Low-chilling pollen sources, such as 'FlordaGrande', III1-5D, and 'EarliGrande', reduce the time required to initiate and reach $80 \%$ germination in medium-low (CII-32) and medium (14-22) chilling requirement genotypes; only III1-5D did not appear to influence germination of the LCR genotypes (112-7).

However, the opposite was true when HCR pollen sources were used ('FlavorCrest' and 'Elegant Lady'). On 112-7 they delayed the time required to reach $80 \%$ germination by almost 2 weeks with respect to the control (self), but distribution of germination on time was not affected. The range of seed germination reflected the degree of contrast in chilling requirement between the progenitors involved in each cross. The seeds -of some genotypes, such as 'Italia-1' and III1-SD, exhibited a dispersed germination, whether selfed or used as pollen donors, while others showed a narrow range when selfed (11-2-7).
This response shows that they are more homozygous with respect to chilling requirement and suggests a quantitative inheritance of chilling requirement. Adaptation for this environment with relatively late winter-early spring frosts is expressed by the proportion of seeds germinating after 70 days under stratification. LCR seed parents produced lategerminating seeds 'only when HCR pollen sources were used. Even though germination was drastically accelerated (3 weeks with respect to selfed seeds) whenever the MCR parent 14-22 was pollinated with LCR genotypes, such as 'EarliGrande' and III1-5D, a small proportion of seeds still required 6.5 to 70 days of stratification that may result in seedlings showing late blooming.

Monitoring seed germination in families covering a wide range in chilling requirement seems to be an important tool for any breeding program starting with a wide genetic base. This correlative response will aid in the formation of groups according to chilling requirement and blooming season and will increase the efficiency of selection and enhance the choice of genotypes to be tested for adaptation over a wide range of altitudes, as found in the tropics and subtropics.

\section{Literature Cited}

Chang, S. and D.J. Werner 1984. Relationship of seed germination and respiration during stratification with cultivar chilling requirement in peach. J. Amer. Soc. Hort. Sci. 109:42-45.

Diaz, D.H. and G.C. Martin. 1972. Peach seed dormancy in relation to endogenous inhibitors and applied growth substances. J. Amer. Soc.
Hort. Sci. 97:651-654.

Futuyma, D.J. and M. Slatkin. 1983. Coevolution. Sinauer \& Assoc., Inc. Sunderland, Mass.

Grant, V. 1981. Plant speciation. Columbia Univ. Press, New York.

Guerriero, R. and G. Scalabrelli. 1985. Effect of stratification duration on seed germination of several peach line rootstocks. Acta Hort. 173:211-221.

Kester, D.E. 1969. Pollen effects on chilling requirements of almond-peach hybrid seeds. J. Amer. Soc. Hort. Sci. 94:318-321.

Kester, D.E., R. Raddi, and R. Assay. 1977. Correlation of chilling requirement for germination, blooming and leafing within and among seedling populations of almond. J. Amer. Soc. Hort. Sci. 102:145-148.

Pasternak, G. and L.E. Powell. 1980. Chilling requirements of apple seeds from cultivars having low and high chilling requirements for shoot growth. HortScience 15:408. (Abstr.)

Pérez, S. 1988. El cultivo del melocotonero en México. Frut Revista de Fruticultura. Barcelona, España. p. 111:157-161.

Pérez, S. 1989. Characterization of Mexican peach populations from tropical and subtropical regions. Acta Hort. 254:139-144.

Rodriguez, A.J. and W.B. Sherman. 1985. Relationships between parental, seed, and seedling chilling requirement in peach and nectarine. J. Amer. Soc. Hort. Sci. 110:627-630.

Solbrig, O.T. (ed.). 1980. Demography and evolution in plant populations. Bot. Monogr. \#15, Univ. of Calif. Press., Berkeley.

Stebbins, G.L. 1950. Variation and evolution in plants. Columbia Univ. Press, New York.

Westwood, M.N. and H.O. Bjornstad. 1968 Chilling requirement of dormant seed of 14 pear species as related to their climatic adaptation. Proc. Amer. Soc. Hort. Sci. 92:141-149. 